\title{
Editorials
}

\section{Calling time on the 10-minute consultation}

Many GPs will be concerned by the recent announcement from the government's advisers, the NHS Future Forum, that:

\section{'Every healthcare professional should} "make every contact count": use every contact with an individual to maintain or improve their mental and physical health and wellbeing where possible, in particular targeting the four main lifestyle risk factors: diet, physical activity, alcohol and tobacco whatever their specialty or the purpose of the contact."

The Forum urges a "transformation in the relationship' between medical staff and patients and suggests health staff routinely talk to patients about their lifestyles, even when they are suffering an unrelated illness, and offer them advice to become healthier. The Forum suggests this responsibility should be included in the NHS Constitution.

Contrast this view with that of the current president of the Royal College of General Practitioners in 1995:

'I believe that all my patients are now fully informed of the dangers of smoking. Sadly many continue to smoke because they lead lives which are so materially and emotionally constrained that cigarette smoking is one of pitifully few sources of pleasure and relief. ... Health differentials based on social class are blamed on lifestyle choices, the victims are blamed, and responsibility for reducing cigarette smoking land obesity, and alcohol consumption) is passed to the GP who must raise the subject, to the point of becoming very tedious on every possible occasion."

\section{CHANGING SCOPE OF THE MEDICAL INTERVIEW}

Three papers in this month's BJGP and one in a forthcoming issue provide an eclectic snapshot of some of the many problems facing modern GPs as they attempt to get the best out of the medical interview for their patients in a changing world. While so many aspects of medical practice have been altered by medical, political, and societal developments in recent years, the timing and constraints of the general practice surgery seem to have remained remarkably constant. It is time we took a fresh look at how the medical interview is organised to suit modern medical practice and the implications for GPs and politicians.

\section{EXPLAINING RISK}

Two of the papers explore the difficulties of explaining and understanding statistics. The first by Edwards et al, to be published in a future issue, looks at the communication of risk to patients. ${ }^{3}$ The move towards shared decision making and avoiding paternalism cannot be achieved without careful attention to risk discussion. The authors describe best practice in this field and the need for GPs to expend time and work skilfully with patients so that they can make informed choices about long-term treatments and behavioural changes.

In the second paper, Froud et al explore the problems that clinicians face in interpreting research trials and using information in medical decision making. ${ }^{4} \mathrm{As}$ Gigerenzer has eloquently demonstrated, many doctors have considerable problems in understanding even simple concepts in statistics. ${ }^{5}$ Froud et al found that some clinicians do not understand the use of relative risk instead of absolute risk to 'frame' and maximise the apparent efficacy of treatments in the reporting of trials. Yet this is one of the most basic problems in risk explanation to patients: if you cannot explain risk effectively, you cannot undertake shared decision making. So there is both an educational need for the modern practitioner to be able to undertake risk communication effectively and also a structural need for more time in modern consultations to achieve this task.

\section{OPPORTUNISTIC PATIENT EDUCATION}

In the third paper, Abildsnes et al shed some insight into the power and control of the consultation and the requirement for health behaviour change consultations to be a subtle meeting of minds of patients and doctors working together. ${ }^{6}$ They carefully point out that the opportunistic introduction of health behaviour change into a consultation that has been booked by the patient for another reason places the practitioner in a position of power, even if the opportunistic approach is intended for the patient's benefit. Introduced with empathy, as a starting point for respectful negotiations, opportunistic approaches may disclose new options, and be appreciated by the patient. Introduced with paternalism, they may overrule patients' values, cause intimidation, and be ineffective.

Two considerations emanate from this discussion. The first is how and when to introduce opportunistic health behaviour change discussions into consultations with patients. The blanket approach of introducing health behaviour change on every occasion will be perceived by patients as intrusive. But done at the correct 'golden moment', when the patient is receptive, it can be highly fruitful and valued. The second is providing the time within general practice to achieve this effectively. Although many of these discussions can be delegated to other members of the team, the initial consultation where the discussion is initiated is of paramount importance and need to be undertaken carefully.

\section{PRIORITISING CONTINUITY}

Ridd et al look at another challenge of modern medical practice: the need for ongoing relationships and continuity of care in effective general practice. ${ }^{7}$ Their study provides evidence of a weak association between patient-doctor depth of relationship and detection of psychologically distressed patients. Continuity of care has become an endangered species throughout the NHS. In hospitals it has been destroyed by changes in junior doctor hours because of the European working time directive. When combined with short turnarounds for admissions, GPs now have to take increased responsibility for the coordination of patient care on discharge.

Continuity of care in general practice itself is under increasing pressure as a direct and unintended result of changes in 


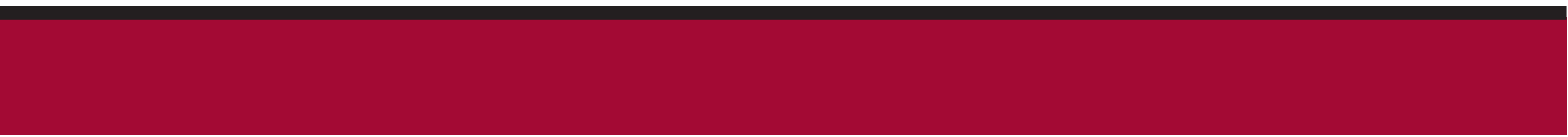

\section{"If GPs are going to address their patients' presenting symptoms and concerns, detect cancers early, ensure safe polypharmacy, coordinate the use of secondary care services, share decisions and communicate risks, and tackle obesity, they are going to need longer consultations.}

working patterns such as part-time working, the employment of salaried doctors, and the expansion of the nurse practitioner role. Political developments, such as enhanced access, prioritise other outcomes above continuity: the patient is encouraged to accept an appointment today with a doctor they don't know rather than an appointment next week with the doctor who knows them and their problems.

\section{INNOVATION IN CONSULTATION LENGTH}

There have been many recent developments in the structure of general practice which have placed intense pressure on the 10-minute consultation. While the patient's agenda should be foremost, high-quality prevention, chronic disease management, and health behaviour modification are important considerations. But under current time constraints, these all push GPs towards a directing rather than a guiding style. Although many GPs vary the consultation length in the context of an overall structure of ' 10 minutes per patient', the risk is that some patients get an inappropriately short consultation as GPs try to catch up after longer consultations. We believe it is time for reflection, innovation, and new research into the lengths of consultations provided to patients. Why particular individuals consult and how often they do so is complex.

While consultation rates overall are increasing, consultation rates with GPs are relatively stable, while house calls have declined, and telephone consultations have increased, ${ }^{8}$ perhaps leaving time for innovation. There is evidence that patients, if offered a choice, are reasonably good at identifying whether they need a short, medium, or long consultation. ${ }^{9}$ More importantly, in longer consultations (10 minutes or more) more psychosocial problems are recognised, more long-term problems are dealt with, more health promotion occurs, ${ }^{10}$ and there may be less GP stress.11

If GPs are going to address their patients' presenting symptoms and concerns, detect cancers early, ensure safe polypharmacy, coordinate the use of secondary care services, share decisions and communicate risks, and tackle obesity, they are going to need longer consultations. We need to investigate how much of our consultations can be shifted to telephone or electronic communication lincluding data gathering for the Quality and Outcomes Framework) to free us up, so that when patients do need a face-to-face consultation there is adequate time for the tasks of modern general practice. Whatever the solution, it is hard to believe that in 20 years time, GPs will still be consulting patients largely face to face but for only 10 minutes at a time.

\section{Jonathan Silverman,}

Associate Clinical Dean, University of Cambridge, School of Clinical Medicine, Addenbrooke's Hospital, Cambridge.

\section{Paul Kinnersley,}

Professor, Cochrane Institute of Primary Care and Public Health, Cardiff University, Primary Care and Public Health, Neuadd Meirionydd, University Hospital of Wales, Cardiff.

\section{Provenance}

Commissioned; not externally peer reviewed.

DOI: 10.3399/bjgp12X625102

\section{ADDRESS FOR CORRESPONDENCE}

Jonathan Silverman

University of Cambridge, School of Clinical Medicine, Addenbrooke's Hospital, Hills Road, Cambridge, CB2 OSP, UK.

E-mail: js355amedschl.cam.ac.uk

\section{REFERENCES}

1. Mooney H. Doctors are told to 'make every contact count' to reduce costs of poor lifestyles. BMJ 2012; 344: e319.

2. Heath I. The mystery of general practice. London: The Nuffield Provincial Hospitals Trust, 1995.

3. Edwards A, Ahmed H, Naik G Communicating risk to patients and the public. Br J Gen Pract 2012; in press.

4. Froud R, Underwood M, Carnes D, Eldridge S. Clinicians' perceptions of reporting methods for back pain trials: a qualitative study. Br J Gen Pract 2012; DOI: 10.3399/bjgp12X630034.

5. Gigerenzer G. Reckoning with risk: learning to live with uncertainty. London: Penguin Books, 2003

6. Abildsnes E, Walseth LT, Flottorp SA, Stensland PS. Power and powerlessness: GPs' narratives about lifestyle counselling. $\mathrm{Br}$ $J$ Gen Pract 2012; DOI: 10.3399/bjgp12X630043

7. Ridd M, Lewis G, Peters TJ, Salisbury C. Detection of patient psychological distress and longitudinal patient-doctor relationships: a cross-sectional study. Br J Gen Pract 2012; DOI: 10.3399/bjgp12X630052.

8. Hippsley Cox J, Jumbu G. Trends in consultation rates in general practice 19952007: analysis of the QRESEARCH database. NHS Information Centre, 2008.

9. Lowenthal L, Bingham E. Length of consultation: how well do patients choose? JR Coll Gen Pract 1987; 37(304): 498-499.

10. Howie JG, Porter AM, Heaney DJ, Hopton JL. Long to short consultation ratio: a proxy measure of quality of care for general practices. Br J Gen Pract 1991; 41(343): 48-54

11. Mercer SW, Fitzpatrick B, Gorlay G, et al. More time for complex consultations in a high-deprivation practice is associated with increased patient enablement. $\mathrm{Br} J \mathrm{Gen}$ Pract 2007; 57(545): 960-966. 